\title{
Survival of AIDS Patients and Characteristics of Those Who Died Over Eight Years of Highly Active Antiretroviral Therapy, at a Referral Center in Northeast Brazil
}

\author{
Ladjane Santos Wolmer de Melo ${ }^{1}$, Heloisa Ramos Lacerda ${ }^{1,2,3}$, Eduardo Campelo ${ }^{4}$, \\ Emanuel Moraes ${ }^{4}$ and Ricardo Arraes de Alencar Ximenes ${ }^{3}$ \\ ${ }^{1}$ Postgraduate Course in Sciences of Health; ${ }^{2}$ Infectious and Parasitic Diseases Clinic, Hospital das Clínicas; ${ }^{3}$ Postgraduate Course on Tropical \\ Medicine; ${ }^{4}$ BSc in Medicine; Federal University of Pernambuco, Recife, PE, Brazil
}

\begin{abstract}
Introduction of highly active antiretroviral therapy has resulted in a significant reduction in morbimortality and significant changes in the causes of death among HIV/AIDS patients. For this reason, it has become essential to monitor survival and causes of death. We constructed a survival curve based on 597 adult patients notified as AIDS cases between 1997 and 2004, at the Hospital das Clínicas, Federal University of Pernambuco, Recife, Brazil. Among those patients, 150 (25\%) progressed to death by December, 2005. Of these, 119 were studied in detail. The data were collected from notification files of the State Health Department and the State Mortality Information System, and were complemented by analysis of medical records. These 597 patients had a survival rate of $88 \%, 86 \%$ and $82 \%$ after one, two and five years, respectively, and a $75 \%$ likelihood of surviving to 1,984 days (66 months). Most of the deaths occurred during the first months after the diagnosis (median, 129 days). Patients who died were predominantly young men who had sexual exposure and came from Recife (the state capital) or its metropolitan region. When the patients were first seen, a large proportion had already presented severe signs of immunodeficiency. Comparing the patients within this group, the characteristics that were associated with lower survival were: male sex, hemoglobin $<10 \mathrm{mg} / \mathrm{dL}$, lymphocytes $<1,000 / \mathrm{mm}^{3}$, use of fewer therapeutic drugs and antiretroviral regimens and non-introduction of protease inhibitors. Most of them died from AIDS-related diseases, particularly undefined respiratory infections. Key-Words: AIDS, survival, cause of death, Brazil.
\end{abstract}

With the advent of highly active antiretroviral therapy (HAART), the clinical manifestations resulting from HIV infection have become less frequent and there has been a substantial improvement in the prognosis for AIDS patients [1,2]. Today, there are around 170,000 HIV/AIDS patients undergoing antiretroviral treatment in Brazil. Reductions in mortality, from $70 \%$ to $40 \%$, and in morbidity, from $80 \%$ to $60 \%$, over the period from 1996 to 2005, have been observed [3]. However, to achieve prolonged success from this therapy, a high degree of adherence is necessary, and viral resistance to and toxicity of HAART have to be overcome [4,5]. Moreover, the results of the universal access to treatment that is available through the Brazilian national health system are still not uniform, since not everyone is able to get rapid access to diagnosis and treatment and there are individuals with certain epidemiological characteristics who, even when treated, present lower survival [6].

In many centers around the world, after treatment with HAART has been instituted, the number of deaths from causes not directly related to HIV/AIDS has increased [7]. Furthermore, regional differences may influence in survival and in the results of HAART regimens. We initiated our study with the aim of determining the survival, cause of death, initial presentation of the disease and progression of AIDS patients

Received on 3 January 2008; revised 16 June 2008.

Address for correspondence: Dr. Ladjane Santos Wolmer de Melo. Avenida Bernardo Vieira de Melo, 2570, Apto 1401, Jaboatão do Guararapes, Pernambuco, Brazil. Zip code: 54410-010. E-mail: ladwolmer@terra.com.br.

The Brazilian Journal of Infectious Diseases 2008;12(4):269-277. (C) 2008 by The Brazilian Journal of Infectious Diseases and Contexto Publishing. All rights reserved. when the outcome was death, at a referral service in northeastern Brazil, over a period of eight years of using HAART.

\section{Material and Methods \\ Study Population}

Adult patients at the Hospital das Clínicas, Federal University of Pernambuco (HC-UFPE), Recife, whose cases were notified as AIDS through the Ministry of Health's notification files stored at the State Health Department covering the period from 1997 to 2004, were analyzed. Following this, the deaths that occurred up to December 31, 2005, were traced through the State Mortality Information System (SIM) and were analyzed in accordance with the guidelines given in the tenth edition of the International Classification of Diseases.

\section{Data Collection}

Data collection was performed by means of a standardized form. A detailed review of all the medical records was carried out in order to add to, complete and rectify the data already gathered from the notification files, whenever necessary. In the event of discordant information, the data in the medical records prevailed.

The Ministry of Health considers patients to be AIDS cases when their CD4 lymphocyte count is less than 350 cells/ $\mathrm{mm}^{3}$ and they present opportunistic diseases in accordance with the adapted CDC criteria or a score equal to or greater than 10 points according to the Caracas criteria [8]. The recorded diagnoses of the diseases were as described by the attending physicians in the medical records. The specific treatment instituted following these diagnoses was in 
accordance with the criteria of the Brazilian Ministry of Health. Among these criteria, for seven diseases indicative of AIDS, presumptive criteria based on clinical features and characteristic findings from complementary tests were also used.

To construct the survival curve for all the patients (including those still alive) whose cases were notified between 1997 and 2004, the data from the notification files were used. The starting point was the notification date. Corrections to the notification dates were made when the patients' cases were notified late, i.e. following death or after being started on HAART. In such situations, the time when AIDS appeared and the date of death or when the patient started on HAART were taken into consideration.

Patients were deemed to have abandoned the outpatient clinic if they failed to show up for more than six months. They were deemed to have discontinued their antiretroviral treatment if they did not use the medication for more than 30 days.

The results of the initial complementary tests were included in the data analysis only if the tests were carried out within one month of the first consultation. At the time of death, the complementary tests carried out during the three previous months were taken into consideration. The CD4 lymphocyte count was obtained by means of flow cytometry, and the HIV viral load was quantified by means of the polymerase chain reaction, using the NASBA method (nucleic acid-based amplified assay), with a minimum detection value of 400 copies $/ \mathrm{mL}$. These tests were carried out at the Central Public Health Laboratory of Pernambuco (LACEN).

\section{Statistical Analysis}

In the first part of the analysis, a survival curve was constructed for the whole population over the study period (including the notified cases that were still alive). The length of survival was defined as the period between the date when the AIDS case was notified to the Ministry of Health and death (the event of interest). Cases in which the known length of survival was zero were excluded, since their inclusion might have distorted the analysis.

Next, a descriptive analysis was made of the patients who progressed to death. Also, with the sole aim of raising hypotheses, survival curves were drawn up for the group that progressed to death in order to make comparisons between the categories of the variables investigated within this group. The survival curves and statistical summary (medians and quartiles) were constructed using the Kaplan-Meier method [9]. The Log-rank test was used to compare the estimated survival curves [9]. A descriptive analysis was performed using Epi-Info software, version 6.04, and SPSS version 8 was used for the survival curves.

Authorization for this study was obtained from the Ethics Committee of the Health Sciences Center, under protocol No. 014/06.

\section{Results}

Survival Analysis

Based on analysis of all the patients whose cases were notified over the study period, we obtained a curve of the deaths, which occurred mainly in the first quartile, i.e. up to the $75^{\text {th }}$ percentile. The probability of survival for this population was $88 \%, 86 \%$ and $82 \%$ for one, two and five years, respectively. There was a $75 \%$ probability of survival for up to 1,984 days (66 months) (Figure 1 ).

The survival curve constructed for the group that progressed to death showed that these patients lived for a median of 129 days (Figure 2).

\section{Patient Characteristics}

Among the 597 patients at HC-UFPE whose cases were notified as AIDS, 150 (25\%) progressed to death. Thirty-one medical records could not be found, and for this reason these cases were discarded (loss of 20\%). Thus, 119 patients remained for the analysis of the deaths.

Most of the patients who died were male (75.6\%) and had darkish or white skin (72.3\%). The patients' mean age was $37.9 \pm 0.9$ years, $60.8 \%$ had less than eight years of schooling, and most came from Recife (the state capital) or its metropolitan region (84.9\%).

At the first consultation, the vast majority of the patients (90.8\%) presented symptoms of manifestations of HIV/AIDS, and $54.9 \%$ had their first consultation at the hospital. The most frequent exposure category was sexual exposure (84\%). At the first consultation, only 21 patients (17.1\%) were not included in AIDS diagnoses that were in accordance with any criteria for defining AIDS (CDC, adapted CDC or Caracas). The main manifestations at the initial presentation were cachexia (74.1\%), fever (51.9\%), asthenia (50.9\%), diarrhea (46.3\%) and coughing (41.7\%).

CD4 lymphocyte counts and viral load quantification before treatment were obtained from 48 and 31 of the medical records, respectively. Of these, only a few (seven and five patients, respectively) had a CD4 T-lymphocyte count equal to or greater than 350 and a viral load of less than 400 . The hemoglobin value was below 10 in $33.6 \%$ of the cases, and the initial total lymphocyte count was less than 1,000 in $48.7 \%$. Renal function was abnormal in $9.2 \%$ of the patients.

Among the patients, 109 (91.6\%) made use of HAART, but $64(58.7 \%)$ had used it for less than six months and 33 (30.3\%) for less than one month. Seventy-one patients (65\%) used a regimen that contained a protease inhibitor; $18.5 \%$ of the patients abandoned the outpatient clinic (Table 1).

HIV/AIDS-related diseases were diagnosed during the progression in $97.4 \%$ of the patients, and in $46.2 \%$ there were three or more of these illnesses (Table 2). The most frequent of these are shown in Figure 3. The mean number of AIDSrelated diseases per patient was $2.55 \pm 1.66$.

Other diseases that were frequently observed during the patients' progression included: alcoholism (18.4\%), acute renal insufficiency (11.7\%), urinary infection (10.9\%), cardiac disease 
Figure 1. Survival analysis for all HIV/AIDS patients at Hospital das Clínicas, UFPE, whose cases were notified between 1997 and 2004.

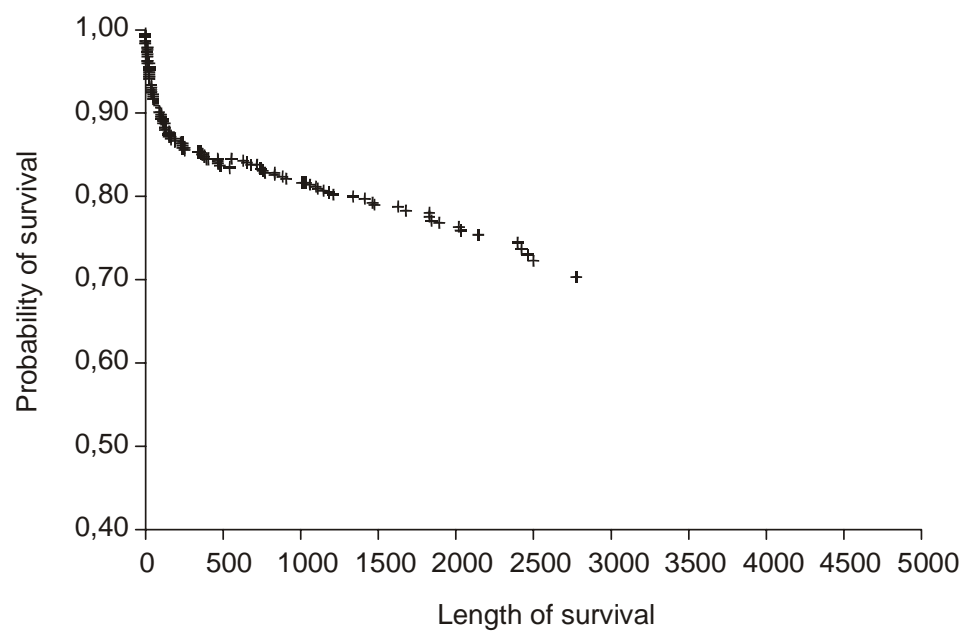

\begin{tabular}{lccc}
\hline Percentiles & 25 & 50 & 75 \\
\hline Time (in days) & - & - & 1984 \\
Standard error & - & - & 292 \\
\hline
\end{tabular}

Figure 2. Survival analysis for the subgroup of HIV/AIDS patients at Hospital das Clínicas, UFPE, whose cases were notified between 1997 and 2004 and who progressed to death up to December 2005.

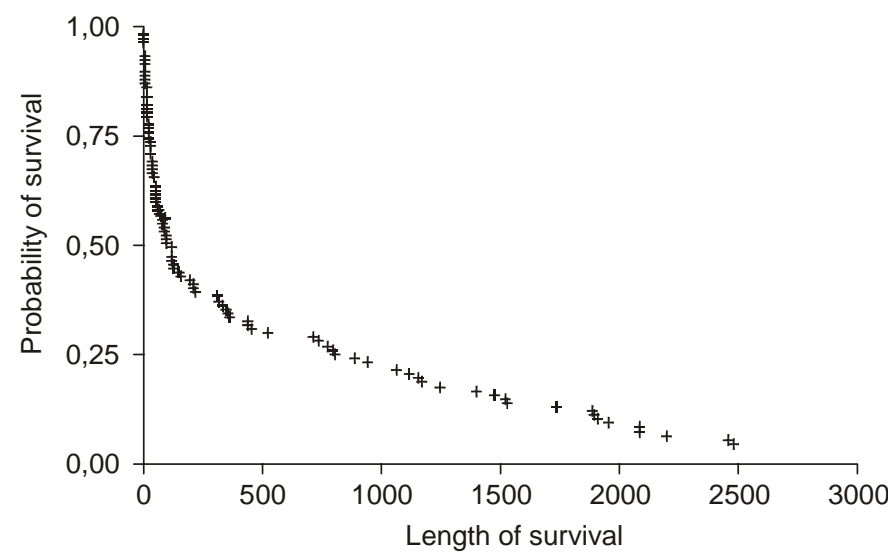

\begin{tabular}{lccc}
\hline Percentiles & 25 & 50 & 75 \\
\hline Time (in days) & 809 & 129 & 25 \\
Standard error & 238.2 & 25.4 & 7.1 \\
\hline
\end{tabular}

\begin{tabular}{|c|c|c|c|c|c|}
\hline \multirow[t]{2}{*}{ Variable } & \multicolumn{3}{|c|}{$\begin{array}{l}\text { Length of survival } \\
\text { (in days) } \\
\text { Percentiles }\end{array}$} & \multirow[t]{2}{*}{$\begin{array}{c}\text { Log-rank } \\
\text { test }\end{array}$} & \multirow[t]{2}{*}{$P$ - value } \\
\hline & 25 & 50 & 75 & & \\
\hline \multicolumn{6}{|l|}{ Sex } \\
\hline Male & & & 1429 & 4.81 & 0.0282 \\
\hline Female & & & 2553 & & \\
\hline \multicolumn{6}{|l|}{ Age group } \\
\hline From 18 to 39 & & & 1938 & 1.97 & 0.1600 \\
\hline 40 or more & & & - & & \\
\hline
\end{tabular}

(8.4\%), anemia (8.4\%), sexually transmitted diseases (8.4\%), psychiatric diseases (5.8\%) and chronic renal insufficiency (5\%). The mean number of these other diseases per patient was $1.3 \pm 1.49$.

\section{Data at the Time of Death}

Ninety-one patients (76.5\%) were having antiretroviral treatment at the time of death, although 60 of them (65.9\%) had been on this treatment for less than six months. AIDS-related diseases were observed in $90 \%$ of the patients at the time of death. The most frequent were respiratory infections of unknown etiology (40\%), tuberculosis (either pulmonary or extra-pulmonary) (18.5\%), cerebral toxoplasmosis (15.5\%), Pneumocystis jiroveci pneumonia (7.7\%), diarrhea (6.2\%), Kaposi's sarcoma (4.5\%) and non-Hodgkin's lymphoma (4.5\%).

For 36 patients (30.2\%), the immediate cause of death was respiratory insufficiency due to respiratory infections, and another six patients (5\%) had respiratory insufficiency that was not a result of infection. Sepsis was the triggering cause of death for 38 patients (32\%), of whom 17 (14\%) had bacterial or nonspecific pneumonia associated with the sepsis. In 13 patients (11\%), diseases of the central nervous system caused death. Thus, among the patients who progressed to death, respiratory infections were directly linked with the immediate cause of death in 59 (49.5\%) of them. Four patients (3.4\%) died due to illnesses not directly related to HIV/AIDS and no information about the circumstances of death was available for eight (8.4\%) (Table 3).

Male gender, having an initial level of hemoglobin of less than $10 \mathrm{mg} / \mathrm{dL}$ or a total lymphocyte count of less than 1,000 / $\mathrm{mm}^{3}$, using antiretrovirals for less than one or less than six months, using less than three antiretrovirals, not using protease inhibitors, using less than three antiretroviral regimens and not giving up attending the outpatient clinic over a period of more than six months were associated with lower survival in this group of patients (Tables 4 and 5). 
Figure 3. HIV/AIDS-related diseases present in the progression in HIV/AIDS patients at Hospital das Clínicas, UFPE, whose cases were notified between 1997 and 2004 and who progressed to death up to December 2005.

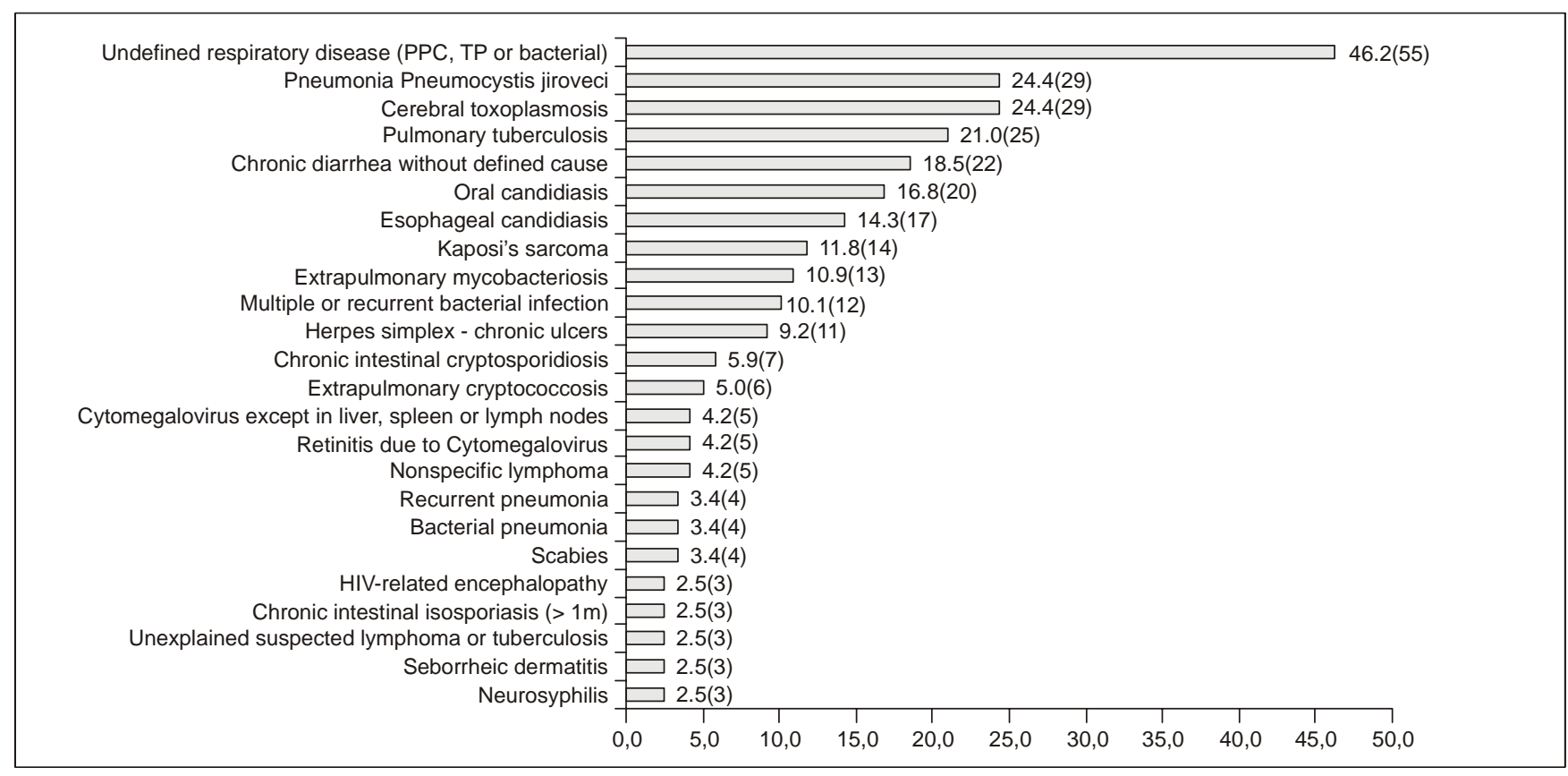

Table 1. Characteristics of the antiretroviral treatment of HIV/AIDS patients whose cases were notified between 1997 and 2004 and who progressed to death up to December 2005.

\begin{tabular}{|c|c|c|}
\hline Antiretroviral treatment & $\mathbf{N}$ & $\%$ \\
\hline \multicolumn{3}{|l|}{ Use of antiretrovirals } \\
\hline Yes & 109 & 91.6 \\
\hline No & 10 & 8.4 \\
\hline \multicolumn{3}{|l|}{ Length of time using antiretrovirals } \\
\hline$<1$ month & 33 & 30.3 \\
\hline 1 to $<3$ months & 17 & 15.6 \\
\hline 3 to $<6$ months & 14 & 12.8 \\
\hline 6 months to $<1$ year & 9 & 8.3 \\
\hline 1 year to $<5$ years & 24 & 22.0 \\
\hline 5 years or more & 12 & 11.0 \\
\hline \multicolumn{3}{|l|}{ Type of regimen } \\
\hline With protease inhibitors & 44 & 40.4 \\
\hline With NNRTIs & 18 & 16.5 \\
\hline With protease inhibitors + NNRTIs & 27 & 24.8 \\
\hline With only NRTIs & 20 & 18.3 \\
\hline \multicolumn{3}{|l|}{ Number of antiretrovirals } \\
\hline From 1 to 2 & 20 & 18.3 \\
\hline From 3 to 6 & 72 & 66.1 \\
\hline 7 or more & 17 & 15.6 \\
\hline \multicolumn{3}{|l|}{ Number of regimens } \\
\hline One & 46 & 42.2 \\
\hline Two & 27 & 24.8 \\
\hline Three & 17 & 15.6 \\
\hline Four or more & 19 & 17.4 \\
\hline \multicolumn{3}{|l|}{ Discontinued follow-up } \\
\hline Yes & 22 & 18.5 \\
\hline No & 88 & 74.0 \\
\hline No information & 9 & 7.5 \\
\hline Total & 109 & 100 \\
\hline
\end{tabular}


Table 2. Diseases present in the progression of HIV/AIDS patients whose cases were notified between 1997 and 2004 and who progressed to death up to December 2005.

\begin{tabular}{lrr}
\hline Variables & $\mathbf{N}$ & $\mathbf{\%}$ \\
\hline Frequency of disease types & & \\
$\quad$ HIV-related diseases & 111 & 97.4 \\
Other diseases & 73 & 61.3 \\
$\quad$ No information & 5 & 4.2 \\
Number of HIV/AIDS-related diseases & 3 & 2.5 \\
$\quad$ None & 83 & 79.8 \\
1 to 3 & 28 & 23.5 \\
3 or more & 5 & 4.2 \\
$\quad$ No information & & \\
Number of other diseases & 96 & 81.7 \\
$\quad$ to 2 & 18 & 10.1 \\
3 or more & 5 & 4.2 \\
$\quad$ No information & $\mathbf{1 1 9}$ & $\mathbf{1 0 0}$ \\
Total & & \\
\hline
\end{tabular}

Table 3. Diseases considered to be triggering factors for death in HIV/AIDS patients at Hospital das Clínicas, UFPE, whose cases were notified between 1997 and 2004.

\begin{tabular}{lll}
\hline Diseases triggering death & $\mathbf{N}$ & $\mathbf{\%}$ \\
\hline HIV/AIDS-related & & \\
Respiratory insufficiency & 42 & 35.2 \\
$\quad$ Of infectious etiology & 36 & 30.2 \\
$\quad$ undefined respiratory infection & 26 & \\
$\quad$ pulmonary tuberculosis & 7 & \\
$\quad$ bacterial pneumonia & 2 & 5.0 \\
$\quad$ Of noninfectious etiology & 6 & 32.0 \\
Sepsis & 38 & 11.0 \\
Infections of the central nervous system & 13 & \\
$\quad$ toxoplasmosis & 6 & \\
$\quad$ cryptococcosis & 4 & \\
$\quad$ tuberculosis & 1 & 3.5 \\
$\quad$ herpes & 1 & 2.5 \\
$\quad$ nonspecific & 1 & 4.2 \\
Hydrolytic-electrolytic disorder & 4 & \\
Upper digestive tract hemorrhage & 3 & 0.8 \\
Other conditions & 5 & 0.8 \\
Unrelated to HIV/AIDS & & 0.8 \\
Lactic acidosis & 1 & 0.8 \\
Cardiac insufficiency due to hyperthyroidism & 1 & $\mathbf{1 0 0}$ \\
Subarachnoid hemorrhage & 1 & \\
Heart valve rupture in rheumatic disease & 1 & 10 \\
No information & $\mathbf{1 1 9}$ & \\
Total & &
\end{tabular}

\section{Discussion}

We investigated the characteristics of AIDS patients who progressed to death in a university hospital, over an eight-year period of using HAART. The entire group of patients (including those who were still alive) whose cases were notified during this period had a $75 \%$ probability of survival till 66 months following notification of the cases to the Ministry of Health. The patients who died were mostly young men with a low level of schooling; their exposure category was almost exclusively sexual. They were mostly from Recife (the state capital) or its metropolitan area and arrived at the clinic presenting significant clinical signs of immunodeficiency. Among these patients, those 
Table 4. Survival analysis for the subgroup of HIV/AIDS patients at Hospital das Clínicas, UFPE, whose cases were notified between 1997 and 2004 and who progressed to death up to December 2005.

\begin{tabular}{|c|c|c|c|c|c|}
\hline \multirow[t]{2}{*}{ Variable } & \multicolumn{3}{|c|}{$\begin{array}{l}\text { Length of survival (in days) } \\
\text { Percentiles }\end{array}$} & \multirow[t]{2}{*}{ Log-rank test } & \multirow[t]{2}{*}{ p value } \\
\hline & 25 & 50 & 75 & & \\
\hline \multicolumn{6}{|l|}{ Sex } \\
\hline Male & 470 & 100 & 20 & \multirow[t]{2}{*}{6.37} & \multirow[t]{2}{*}{0.0116} \\
\hline Female & 1191 & 339 & 65 & & \\
\hline \multicolumn{6}{|l|}{ Age group } \\
\hline 18 to 39 & 975 & 119 & 25 & \multirow[t]{2}{*}{1.61} & \multirow[t]{2}{*}{0.2040} \\
\hline 40 or more & 398 & 129 & 29 & & \\
\hline \multicolumn{6}{|l|}{ Schooling } \\
\hline$<8$ years & 831 & 122 & 19 & \multirow[t]{2}{*}{0.04} & \multirow[t]{2}{*}{0.8405} \\
\hline 8 years or more & 975 & 154 & 38 & & \\
\hline \multicolumn{6}{|c|}{ Criteria for case definition at initial presentation } \\
\hline None & 1,191 & 65 & 20 & \multirow[t]{2}{*}{0.02} & \multirow[t]{2}{*}{0.8932} \\
\hline At least one & 553 & 131 & 29 & & \\
\hline \multicolumn{6}{|c|}{ Criteria for initial case definition - Caracas } \\
\hline Yes & 470 & 131 & 29 & \multirow[t]{2}{*}{0.50} & \multirow[t]{2}{*}{0.4812} \\
\hline No & 1,205 & 119 & 20 & & \\
\hline \multicolumn{6}{|l|}{ Hemoglobin } \\
\hline$<10$ & 227 & 52 & 20 & \multirow[t]{2}{*}{7.0} & \multirow[t]{2}{*}{0.0081} \\
\hline$>10$ & 1,153 & 154 & 20 & & \\
\hline \multicolumn{6}{|l|}{ Lymphocytes } \\
\hline$<1,000$ & 339 & 65 & 19 & \multirow[t]{2}{*}{7.88} & \multirow[t]{2}{*}{0.0050} \\
\hline 1,000 or more & 1,280 & 246 & 36 & & \\
\hline \multicolumn{6}{|l|}{ Antiretrovirals } \\
\hline$<3$ & 227 & 50 & 14 & 7.41 & 0.0065 \\
\hline 3 or more & 975 & 131 & 34 & & \\
\hline Antiretroviral regim & & & & & \\
\hline$<3$ & 159 & 52 & 15 & 45.98 & 0.0000 \\
\hline 3 or more & 1,925 & 1,153 & 246 & & \\
\hline Use of protease inh & & & & & \\
\hline Yes & 1,205 & 154 & 39 & 14.5 & 0.0001 \\
\hline No & 227 & 50 & 14 & & \\
\hline Discontinued treatn & & & & & \\
\hline Yes & 1,765 & 975 & 469 & 7.1 & 0.0077 \\
\hline No & 351 & 56 & 17 & & \\
\hline Antiretroviral treatr & & & & & \\
\hline$<6$ months & 100 & 36 & 14 & 108.1 & 0.0000 \\
\hline$>6$ months & 1,915 & 1,096 & 398 & & \\
\hline Antiretroviral treatr & & & & & \\
\hline$<1$ month & 20 & 14 & 05 & 101.7 & 0.0000 \\
\hline$>1$ month & 1,191 & 254 & 100 & & \\
\hline
\end{tabular}

who had been using antiretrovirals, including protease inhibitors, for more than six months had the greatest survival. Likewise, those who had been using multiple drug regimens and who arrived with an initial presentation of normal hemoglobin and total lymphocyte levels showed the highest rate of survival. The deaths were predominantly caused by HIV/AIDS-related diseases and occurred during the first few months after diagnosis.
Because these were secondary data, it is possible that information bias may have occurred, mainly due to omissions in the case notes. However, the use of a standardized form for collecting data from the medical records, the participation of trained researchers and the fact that the patients had been seen in a university hospital under due supervision should have minimized such bias. However, the inexistence of CD4 lymphocyte counts and viral load quantification in the medical 
Table 5. Survival analysis for the subgroup of HIV/AIDS patients at Hospital das Clínicas, UFPE, whose cases were notified between 1997 and 2004 and who progressed to death up to December 2005, in relation to associated diseases.

\begin{tabular}{|c|c|c|c|c|c|}
\hline \multirow[t]{2}{*}{ Variable } & \multicolumn{3}{|c|}{$\begin{array}{l}\text { Length of survival (in days) } \\
\text { Percentiles }\end{array}$} & \multirow[t]{2}{*}{ Log-rank test } & \multirow[t]{2}{*}{ p value } \\
\hline & 25 & 50 & 75 & & \\
\hline \multicolumn{6}{|c|}{ Presence of HIV-related diseases } \\
\hline Yes & 484 & 116 & 22 & 1.78 & 0.1823 \\
\hline No & 1,429 & 918 & 840 & & \\
\hline \multicolumn{6}{|c|}{ Presence of other diseases } \\
\hline Yes & 1,562 & 132 & 25 & 1.47 & 0.2256 \\
\hline No & 484 & 122 & 29 & & \\
\hline \multicolumn{6}{|c|}{ Undefined respiratory infection } \\
\hline Yes & 484 & 131 & 34 & 0.00 & 0.9696 \\
\hline No & 918 & 116 & 22 & & \\
\hline \multicolumn{6}{|c|}{ Pneumocistis jiroveci pneumonia } \\
\hline Yes & 975 & 116 & 36 & 2.5 & 0.1132 \\
\hline No & 748 & 131 & 29 & & \\
\hline \multicolumn{6}{|c|}{ Cerebral toxoplasmosis } \\
\hline Yes & 1,280 & 368 & 51 & 4.6 & 0.0313 \\
\hline No & 469 & 100 & 22 & & \\
\hline \multicolumn{6}{|c|}{ Pulmonary tuberculosis } \\
\hline Yes & 1,096 & 192 & 49 & 1.4 & 0.2426 \\
\hline No & 469 & 119 & 21 & & \\
\hline \multicolumn{6}{|c|}{ Cardiac disease } \\
\hline Yes & 1,562 & 36 & 17 & 0.1 & 0.7548 \\
\hline No & 748 & 131 & 30 & & \\
\hline \multicolumn{6}{|c|}{ Alcoholism } \\
\hline Yes & 470 & 36 & 07 & 0.18 & 0.6674 \\
\hline No & 831 & 154 & 37 & & \\
\hline \multicolumn{6}{|c|}{ Acute renal insufficiency } \\
\hline Yes & 975 & 132 & 34 & 0.2 & 0.6360 \\
\hline No & 766 & 122 & 22 & & \\
\hline \multicolumn{6}{|c|}{ Chronic renal insufficiency } \\
\hline Yes & 1,984 & 1,915 & 1,191 & 6.2 & 0.0128 \\
\hline No & 484 & 116 & 22 & & \\
\hline
\end{tabular}

records of many patients prevented the compilation of this information and constituted a significant gap in the data. The absence of these data probably arose because there was insufficient time between hospital admission and death to stabilize the patients' clinical condition or to make immunological and virological evaluations, along with the considerable delay in obtaining the results of such tests. The variables studied, from the patient's initial presentation to death, were compared between categories within the group that progressed to death. Some differences, which will be commented on below, were statistically significant, but this was true only for this group and cannot be generalized. On the basis of the differences found, we have raised some hypotheses that may be explored in a subsequent analytical study that would include all the patients at HC-UFPE whose cases were notified during the same period.

When we examined the survival curve constructed for all the patients whose cases were notified (including those who were still alive), we observed a good survival rate, with a $75 \%$ probability of surviving for up to 1,984 days (66 months). In 2003, Marins published a study comparing the survival of AIDS patients diagnosed in Brazil in 1995 with those diagnosed in 1996. He observed a significant difference, with a mean survival of 18 months in 1995 and 58 months in 1996 (a year marked by the start of HAART use) [2]. In another study, in Rio de Janeiro, Brazil, the 75th percentile survival increased from 14 months among patients diagnosed in 1995 to 46 months among those diagnosed in 1998. The medians for these two times (1995 and 1998) were 35 and 68 months, respectively, with a $74 \%$ probability of survival for one year and $56 \%$ for two years in 1995, and $81 \%$ and 77\%, in 1996 [10]. In Taiwan, an analysis covering the period from 1997 to 2003 showed that patients presented a five-year survival rate of $58 \%$, when they had already been diagnosed with AIDS, and 89\%, when they were still asymptomatic HIV patients [11]. 
The death rate over the period that we studied was 25\%, which is a good result if compared with the rate for AIDS patients for the state of Pernambuco, which was $48.7 \%$ in 1997 and 32.7\% in 2004[12]. On a country-wide basis in Brazil from 1997 to 2004, the death rate was 35\% [8] and in São Paulo from 1996 to 2006 it was 17\%[13]. In Norway, among patients followed up at a university hospital between 1986 and 2005, the death rate was 32\%; it went down from $47 \%$ (over the period from 1986 to 1990) to 11\% between 2001 and 2005[14].

Although the study population came from only one of the three main reference hospitals treating HIV/AIDS patients in the state of Pernambuco, it displayed the same sociodemographic and epidemiological characteristics as in the whole state [12] and country as a whole [8]. That is, the patients were mostly young men whose exposure category was almost exclusively sexual. They came from many municipalities, considering that among the states' 185 municipalities, only 22 have not yet notified any cases [12], although most were from Recife and its metropolitan region.

The categories of variables that were related to lower survival were male sex, hemoglobin level below $10 \mathrm{mg} / \mathrm{dL}$, total lymphocyte count of less than $1,000 / \mathrm{mm}^{3}$, use of lower numbers of antiretrovirals and for less time, nonuse of protease inhibitors and not giving up attending consultations. Support for the hypotheses that were raised was found in the literature. Lower levels of hemoglobin has been shown to be associated with an 88 to $91 \%$ increase in the risk of progression of the disease or death [15], and low hemoglobin has been considered to be a predictive factor for death[16]. The use of HAART, including the use of protease inhibitors, was shown to be an important milestone in reducing mortality, when accessible [1,17]. Also, in a study by Signorini[10] published in 2005, the likelihood of survival increased with the inclusion of more antiretroviral drugs. In Brazil, loss from follow-up was associated with lower survival over the period from 1995 to 2002 [10]. On the other hand, between 1989 and 1992, individuals whose interval between consultations was greater than six months presented a lower risk of progressing to death; this result was attributed to the fact that patients who were more severely affected would be more motivated to seek the health services, despite access difficulties [18]. Moreover, in some cases, antiretroviral use might have been maintained with a good response, even if the medical record does not show that consultations were made. Finally, contrary to our findings, lower survival was found among women in a cohort in the state of São Paulo. In this study, female mortality was greater, even though the women who took part in the study were more frequently asymptomatic and had access to the same care [19].

Among the patients who progressed to death, there was good coverage with regard to antiretroviral use, since $91 \%$ of these patients had been using such therapy. Based on these data, we raise the hypothesis that, since most of these patients arrived showing symptoms, with clear signs of immunodeficiency, and $18 \%$ had a disease that leads to a diagnosis of AIDS, their initial state (which was already advanced) may have influenced in the progression to death
[20]. A study published by Zhou in 2005 [14] corroborated this supposition, pointing out that symptomatic individuals had a 125 to $133 \%$ higher risk of disease progression and death. This delay in starting treatment may be associated with difficulties in access to the means of treatment, personal attitudes towards health or the stigma of the disease, among other factors [21,22] In any case, such delays may significantly alter the prognosis.

Insufficient length of antiretroviral use may also affect the outcome [14]. Thirty-three patients (30\%) used this therapy for less than 30 days, and around 60\% (64 patients) for less than six months. Published studies confirm the need to use antiretrovirals for adequate periods in order to achieve immune system recovery after starting treatment [23]. Therefore, the question of access to and starting treatment needs to be investigated more deeply, considering that despite the fact that most of the patients came from places close to the state capital, they started HAART late and progressed to death over a short period. These patients probably had very low CD4 T-lymphocyte counts, which was indirectly observed through the low total lymphocyte counts among the patients with a lower rate of survival. Around one third of the patients were exhaustively treated, since $16 \%$ used more than four regimens and $14 \%$ used more than seven antiretrovirals, albeit not concomitantly. In these cases, death may have resulted from multiresistance to antiretrovirals, or even from inexorable progression of the disease despite HAART use [20]. Primary resistance does not seem to have occurred in this group, perhaps because it is rare in this region [24]. Non-adherence to the antiretrovirals may also have influenced the result; this was not analyzed, despite its importance [25], because the medical records did not contain complete data on adherence to therapy.

Although it was evident in our study that deaths due to HIV/ AIDS-related diseases were predominant, deaths unrelated to viral infection also occurred. It is believed that, through the use of HAART, there may be changes in the causes of death, as has already occurred in centers in Europe and United States [26-28]. This would be not only because of the complications relating to the toxic effects of antiretrovirals, but also because of the emergence of diseases that may or may not be associated with HIV [29], but which require time to become overt, such as coinfections caused by hepatitis $\mathrm{B}$ and $\mathrm{C}$ viruses and papillomavirus.

Over the course of the disease, a high percentage of patients developed respiratory infections of undefined etiology (46.2\%), and most of the deaths occurred for this reason. Respiratory infections are very frequent among immunocompromised patients [30], and they generally progress to very serious conditions, with a high risk of death. The etiological diagnosis is difficult because the clinical conditions are often atypical [31], and changes in the causal agents have occurred since the advent of HAART [32]. In health services in which the possibilities for etiological investigation are limited [33-35], delays in such investigations result in greater risk of death for these patients [36]. Thus, therapy should be started rapidly and be directed towards the most likely microorganisms $[31,37]$. On the other hand, with clarification of the cause, it is

www.bjid.com.br 
possible to discontinue the medications that are no longer indicated $[38,39]$. In the light of the high frequency and severity of the respiratory conditions that trigger the majority of the deaths, it would be of interest to improve the investigative resources and the treatment for such conditions, since respiratory infections without identified causal agents were clearly related to the deaths in this group of patients.

Because most of the patients were already at an advanced stage when they were admitted to our department and rapidly progressed to death, we believe that more emphasis needs to be given to early access, diagnosis and antiretroviral therapy. Although the care provided and the use of HAART have been shown to be effective for AIDS treatment, with good survival in relation to the total number of patients whose cases were notified over the eight-year period, it is fundamentally important for all patients to be able to start such treatment in good time.

\section{References}

1. Palella F.J. Jr., Delaney K.N., Moorman A.C., et al. Declining morbidity and mortality among patients with advanced human immunodeficiency virus infection. HIV Outpatient Study Investigators. N Engl J Med 1998;338:853-60.

2. Marins J.R., Jamal L.F., Chen S.Y., et al. Dramatic improvement in survival among adult Brazilian AIDS patients. AIDS 2003; $17: 1675-82$.

3. Gianna M.C., Kalichman A. Editorial. JBA 2006;7:1.

4. Lieb S., Brooks R.G., Hopkins R.S., et al. Predicting death from HIV/AIDS: a case-control study from Florida public HIV/AIDS clinics. J Acquir Immune Defic Syndr 2002;30:351-8.

5. Teodor A., Teodor D., Luca V. Side effects of antiretroviral therapy. Rev Med Chir Soc Med Nat Iasi 2004;108:23-6.

6. Saraceni V., Da Cruz M.M., Lauria L. de M., Durovin B. Trends and characteristics of AIDS mortality in Rio de Janeiro city after introduction of highly antiretroviral therapy. The Braz $\mathrm{J}$ Infect Dis 2005;9:209-15.

7. Valdez H., Chowdhry T.K., Asaad R., et al. Changing spectrum of mortality due to human immunodeficiency virus: analysis of 260 deaths during 1995-1999. Clin Infect Dis 2001;32:1487-93.

8. Brazilian Ministry of Health. Boletim Epidemiológico Aids Ano IV

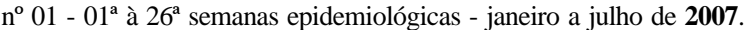

9. Kleinbaum D.G. Survival Analysis: a self-learning text. (Statistics in the health sciences). New York: Springer-Verlag: 1995.

10. Signorini D.J.H.P., Codeço C.T., Carvalho M.S., et al. Effect of sociodemographic and therapeutic procedures on survival of AIDS patients assisted in Brazilian outpatient clinic. Rev Bras Epidemiol 2005;8:253-61.

11. Fang C.T., Chang H.M., Hsu H.M., et al. Life expectancy of patients with newly-diagnosed HIV infection in the era of highly active antiretroviral therapy. QJM. 2007;100:97-105.

12. State Health Department - Pernambuco. Boletim Informativo DST/AIDS, ano VI, n. 2, set 2006.

13. Casseb J., Fonseca L.A., Veiga A.P., et al. AIDS incidence and mortality in a hospital-based cohort of HIV-1-seropositive patients receiving highly active antiretroviral therapy in São Paulo, Brazil. AIDS Patients Care STDS 2003;17:447-52.

14. Bruun J.N., Skeie L., Maeland A., et al. HIV/AIDS - From lethal syndrome to chronic disease. Tidsskr Nor Laegeforen 2006;126:3121-4.

15. Zhou J., Kumarasamy N., TREAT Asia HIV Observational Database. Predicting short-term disease progression among HIVinfected patients in Asia and the Pacific region: preliminary results from the treatment. Asia HIV observational database (TAHOD). HIV Medicine 2005;6:216-23.

16. O’Brien M.E., Kupqa R., Msamanga G.I., et al. Anemia is an independent predictor of mortality and immunologic progression of disease among women with HIV in Tanzania. J Acquir Immune Defic Syndr 2005;40:219-25.
17. Mocroft A., Ledergerber B., Katlama C., et al. Decline in the AIDS and death rates in the Euro SIDA study: an observational study. Lancet 2003;362:22-9.

18. Acurcio F.A., Cesar C.C., Guimarães M.D. Health care utilization and survival among patients with AIDS in Belo Horizonte, Minas Gerais, Brazil. Cad Saude Publica 1998;14:811-20.

19. Braga P., Cardoso M.R., Segurado A.C. Gender differences in survival in an HIV/AIDS cohort from São Paulo, Brazil. AIDS Patient Care STDS 2007;21:321-8.

20. Krentz H.B., Kliewer G., Gill M.J. Changing mortality rates and causes of death for HIV-infected individuals living in Southern Alberta, Canada from 1984 to 2003. HIV Med 2005;6:99-106.

21. Reif S., Golin C.E., Smith S.R. Barriers to accessing HIV/AIDS care in North Carolina: rural and urban differences. AIDS Care 2005; 17:558-65.

22. dos Santos M.A., Albuquerque M.F., Ximenes R.A., et al. Risk factors for treatment delay in pulmonary tuberculosis in Recife, Brazil. BMC Public Health 2005;5:25.

23. Mandell D. Principles \& Practice of Infectious Diseases 6th ed. Philadelphia: Elsevier Churchill Livingstone; 2005.

24. Medeiros L.B., Lacerda H.R., Cavalcanti A.M., Albuquerque M. de F. Primary resistance of human immunodeficiency virus type 1 in a reference center in Recife, Pernambuco, Brazil. Mem Inst Oswaldo Cruz 2006;101:845-9.

25. Mills E.J., Nachega J.B., Bangsberg D.R., et al. Adherence to HAART: a systematic review of developed and developing nation patient-reported barriers and facilitators. PLoS Med 2006; 3:e438.

26. Lu T.H., Chang H.J., Chen L.S., et al. Changes in causes of death and associated conditions among persons with HIV/AIDS after the introduction of highly active antiretroviral therapy in Taiwan. J Formos Med Assoc 2006;105:604-9.

27. Casalino E., Wolff M., Ravaud P., et al. Impact of HAART advent on admission patterns and survival in HIV-infected patients admitted to an intensive care unit. AIDS 2004;18:1429-33.

28. Palella F.R. Jr., Baker R.K., Moorman A.C., et al. Mortality in highly active antiretroviral therapy era: changing causes of death and disease in the HIV outpatient study. J Acquir Immune Defic Syndr 2006;43:27-34.

29. Mocroft A., Brettle R., Kirk O., et al. Changes in the cause of death among HIV positive subjects across Europe: results from the EuroSIDA study. AIDS 2002;16:1663-71.

30. Cowan M.J., Shelahmer J.H., Levine S.J. Acute respiratory failure in the HIV-seropositive patient. Crit Care Clin 1997;13:523-52.

31. Moroni M., Franzetti F. Bacterial pneumonia in adult patients with HIV infection. J Chemother 1995;7:292-306.

32. Wolff A.J., O’Donnell A.E. Pulmonary manifestation of HIV infection in the era of highly active antiretriviral therapy. Chest 2001; 120 : $1888-93$.

33. De Backer A.I., Mortele K.J., De Keulenaer B.L., Parizel P.M. Tuberculosis: epidemiology, manifestations and the value of medical imaging in diagnosis. JBR-BTR 2006;89:243-50.

34. Da Silva R.M., Teixeira P.J., Moreira J. da S. The clinical utility of induced sputum for diagnosis of bacterial community-acquired pneumonia in HIV-infected patients: a prospective crosssectional study. Braz J Infect Dis 2006;10:89-93.

35. Blum T., Roth A., Mauch H., et al. Pneumocystis jiroveci pneumonia in immunocompromised patients without AIDS - a case series. Dtsch Med Wochenschr 2006;131:1515-20.

36. Waite S., Jeudy J., White C.S. Acute lung infections in normal and immunocompromised hosts. Radiol Clin North Am 2006;44:295-315.

37. Rosenberg A.L., Seneff M.G., Atiyeh L., et al. The importance of bacterial sepsis in intensive care unit patients with acquired immunodeficiency syndrome: implications for future care in the age of increasing antiretroviral resistance. Crit Care Med 2001;29:548-56.

38. Huang L., Hecht F.M., Stansell J.D., et al. Suspected Pneumocystis carinii with a negative induced sputum examination. Is early bronchoscopy useful? Am J Respir Crit Care Med 1995; $151: 1866-71$.

39. Gracia J.D., Miravitlles M., Mavordomo C., et al. Empiric treatments impair the diagnostic yield of BAL in HIV-positive patients. Chest 1997;111:1180-6. 